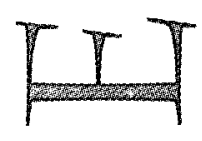

\title{
Guide to Consumers' Pharmaceutical Purchasing Behavior
}
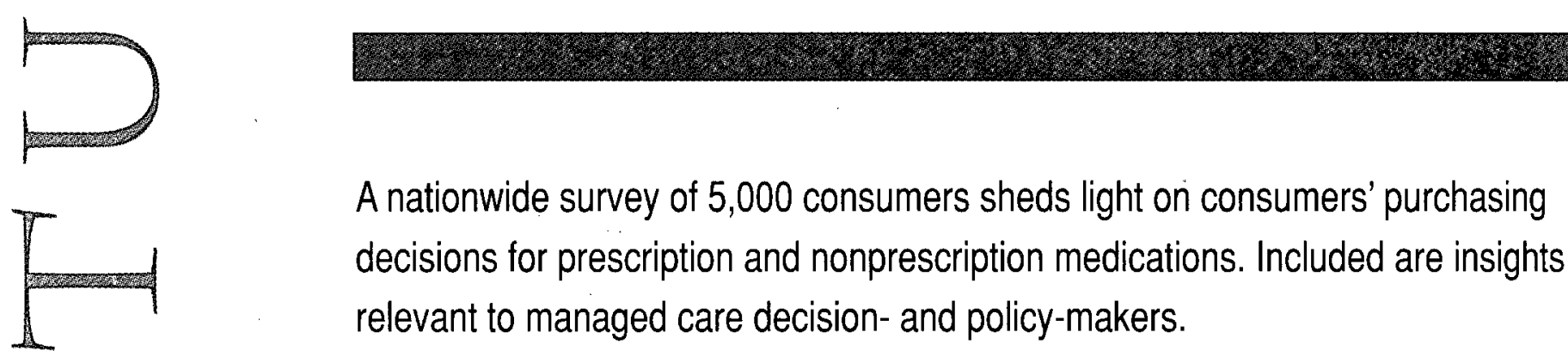

\section{A nationwide survey of 5,000 consumers sheds light on consumers' purchasing decisions for prescription and nonprescription medications. Included are insights relevant to managed care decision- and policy-makers.}
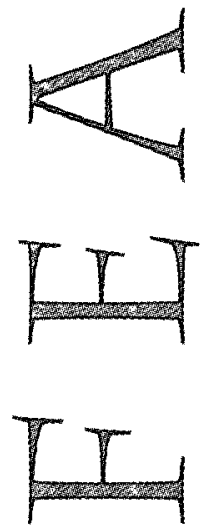

\section{MARSHA FAHEY}

MARSHA FAHEY is a writer and editor, Emron, Inc., Warren, New Jersey.

ACKNowledGment: Based on A.C. Nielsen's Homescan Panel survey. Some portions of these data were reported in the CibaGeneva Pharmacy Benefit Report, 1996 Trends E Forecasts.

Copyright (C) 1996 Academy of Managed Care Pharmacy, lnc. All rights reserved. he pharmaceutical purchasing behavior of consumers is the subject of unending market research for the nation's pharmaceutical companies and managed care organizations (MCOs). Despite the industry's best efforts to predict future trends based on past experiences, consumers continue to confound the prognosticators.

Several issues particularly pertinent to MCOs were explored in a recent consumer survey conducted by Emron, Inc., using the A.C. Nielsen Homescan panel as the survey sample group. In this article, I explore consumers' behaviors relative to medication purchases in these areas:

$\Delta$ Sources of advice about prescription and nonprescription medications

$\Delta$ Communications with prescribers about cost and impact on quality of life $\Delta$ Opinions about price equity of med- 
Table 1. Consumers' Sources of Information about Prescription and Nonprescription Product Use

\begin{tabular}{|c|c|c|c|c|c|c|c|c|}
\hline \multirow[b]{2}{*}{ Type of Respondent } & \multicolumn{8}{|c|}{$\%$ Respondents } \\
\hline & Physician & Pharmacist & Nurse & $\begin{array}{l}\text { Physician } \\
\text { Assistant }\end{array}$ & $\begin{array}{c}\mathbf{R x} \\
\text { Instructions }\end{array}$ & Literature & $\begin{array}{l}\text { Family/ } \\
\text { Friend }\end{array}$ & Other \\
\hline \multicolumn{9}{|l|}{ All patients } \\
\hline Prescription drugs & 83.3 & 71.3 & 15.5 & 9.0 & 72.1 & 8.1 & 0 & 3.3 \\
\hline Nonprescription drugs & 59.6 & 75.1 & 16.0 & 0 & 0 & 21.0 & 18.8 & 6.3 \\
\hline \multicolumn{9}{|l|}{ Managed care patients } \\
\hline Prescription drugs & 82.1 & 71.0 & 14.9 & 9.3 & 73.2 & 7.3 & 0 & 3.3 \\
\hline Nonprescription drugs & 57.9 & 72.4 & 17.3 & 0 & 0 & 21.7 & 22.1 & 7.6 \\
\hline \multicolumn{9}{|l|}{ Indemnity patients } \\
\hline Prescription drugs & 84.6 & 73.2 & 15.3 & 7.1 & 73.6 & 9.2 & 0 & 3.5 \\
\hline Nonprescription drugs & 54.0 & 76.3 & 14.5 & 0 & 0 & 20.1 & 19.8 & 6.0 \\
\hline \multicolumn{9}{|l|}{ Medicare patients } \\
\hline Prescription drugs & 87.2 & 69.7 & 16.7 & 8.7 & 67.2 & 7.8 & 0 & 2.7 \\
\hline Nonprescription drugs & 76.5 & 76.7 & 13.9 & 0 & 0 & 18.5 & 8.6 & 3.2 \\
\hline \multicolumn{9}{|l|}{ Medicaid patients } \\
\hline Prescription drugs & 78.1 & 81.3 & 25.0 & 17.7 & 74.0 & 10.4 & 0 & 4.2 \\
\hline Nonprescription drugs & 61.5 & 90.8 & 26.2 & 0 & 0 & 18.5 & 21.5 & 6.2 \\
\hline
\end{tabular}

ications

$\Delta$ Importance of the pharmacy benefit in health plans

$\Delta$ Role of advertising in purchasing decisions for nonprescription medications

\section{SOURCES OF ADVICE FOR CONSUMERS}

As any practicing pharmacist can attest, consumers do not rely solely on their physicians for advice about prescription medications; in fact, some do not even talk to physicians about the prescription. As shown in Table 1, Medicaid patients more often go to pharmacists for advice than to physicians.

Those with traditional insurance and those in managed care plans also gather information from multiple sources: $83 \%$ talk to the physician; while $71 \%$ also consult pharmacists. Reassuringly, $72 \%$ say they read prescription instructions.

More managed care consumers than indemnity consumers talk to medical support staff-nurses or physician assistants (15\% of indemnity and $25 \%$ of managed care consumers consult nurses; $7 \%$ of indemnity and $18 \%$ of managed care consumers consult a physician assistant). These figures probably reflect the wider range of health care professionals available to the managed care consumer at the primary care level.

Michael Dillon, M.S., R.Ph., pharmacy director of Community Health Plan in Latham, New York, says he is pleased but surprised by the study results on the number of consumers who turn to their pharmacist for advice. "Considering the business diversity in the field, the many ways prescriptions are dispensed-chain and independent pharmacies, supermarkets, mail service, clinics, long-term care facilities-these figures are a validation of the traditional role of the pharmacist."

Supporting the apparent value consumers place on advice from pharmacists are data indicating that $48 \%$ of those in this survey believe their pharmacists should have access to information about the patient's overall health status. As would be expected, considering their higher dependence upon the pharmacist for information about using medication, even more Medicaid patients regard this criteria as important (60\%).

Allan Chernov, M.D., vice president of medical services for southwestern operations of Prudential HealthCare, is glad to see such an expression of confidence in pharmacists. "In managed care, we have tried to create an environment in which people see health care
Table 2. Most Frequent Consumer Purchasing Behavior at Point-of-Prescription Dispensing

\begin{tabular}{lc}
\hline $\begin{array}{l}\text { Consumer Request } \\
\text { about Prescription }\end{array}$ & $\%$ Respondents \\
\hline $\begin{array}{l}\text { Fill prescription as } \\
\text { physician has written }\end{array}$ & 42.7 \\
Fill prescription as & \\
pharmacist deems & \\
appropriate & 20.8 \\
Request generic product & 17.7 \\
Request brand-name product & 2.5 \\
Base decision on cost & 9.2 \\
\end{tabular}

and the people who provide it as members of a team that encompasses the entire continuum of a patient's care. Figures such as these show that the pharmacist is viewed as a member of that team-a member contributing to decisions about patient care and treatment."

An even more telling expression of faith in the pharmacist is consumers' behavior at the point of purchase (Table 2). When filling a prescription, only $43 \%$ ask to have it filled as written, while $21 \%$ allow the pharmacist to fill the prescription with the brand he or she chooses. Indemnity patients are even more laissez faire (24\%) than managed care patients (20\%) in allowing the pharmacist to fill prescriptions with the

Continued on page 494 
Table 3. Household Expenditures per Month for Prescription Medications by Survey Respondents

\begin{tabular}{lcccc}
\hline $\begin{array}{l}\text { Prescription } \\
\text { Expenditures }\end{array}$ & $\begin{array}{c}\text { All } \\
\text { Plans }\end{array}$ & $\begin{array}{c}\text { Managed } \\
\text { Care Plans }\end{array}$ & $\begin{array}{c}\text { Indemnity } \\
\text { Plans }\end{array}$ & $\begin{array}{c}\text { Medicare } \\
\text { Plans }\end{array}$ \\
\hline$\leq 10$ & 46.2 & $\mathbf{4 8 . 9}$ & 45.0 & 32.2 \\
$11-50$ & 37.7 & 41.1 & 37.3 & 34.3 \\
$51-100$ & 8.4 & 5.9 & 10.4 & 15.1 \\
$>100$ & 6.1 & 3.1 & 5.9 & 15.4 \\
Do not know & 1.6 & 1.0 & 1.3 & 3.1 \\
\hline
\end{tabular}

Table 4. Frequency of Provision of Wellness and Disease-Management Programs by Type of Plan

\begin{tabular}{lccc}
\hline & \multicolumn{3}{c}{$\%$ Respondents } \\
\cline { 2 - 4 } Categories of Responses & All Plans & Managed Care Plans & Indemnity Plans \\
\hline Yes, someone in household participates. & & & 28.6 \\
$\quad$ Wellness & 24.6 & 3.8 & 2.1 \\
$\quad$ Disease management & 3.2 & & \\
$\quad$ Yes, no one in household participates. & & 22.6 & 10.6 \\
$\quad$ Wellness & 16.2 & 16.3 & 6.7 \\
$\quad$ Disease management & 11.4 & & 44.3 \\
No. & & 23.6 & 43.1 \\
$\quad$ Wellness & 33.1 & 29.6 & 25.1 \\
$\quad$ Disease management & 36.3 & & 48.1 \\
Do not know. & & 25.3 & \\
$\quad$ Wellness & 26.1 & 50.3 & \\
Disease Management & 49.1 & & \\
\end{tabular}

most appropriate product. Only

Medicare patients show more interest in requiring the pharmacist to fill prescriptions as written (51\%).

Further, the purchaser is not making requests at point of purchase based on cost or on brand loyalty. Only $9 \%$ say they base their buying decisions on cost differentials; only $2.5 \%$ request brand-name products. Consumers, however, are aware that they have the option to fill prescriptions with generics-only one fifth say they have never requested a generic product to decrease the cost of their prescription.

No matter what the source of information, consumers feel satisfied that they are adequately informed ( $94 \%$ overall, consistent across all insurance types and regions). But are they? More than $90 \%$ get information about dosing, but only $60 \%$ get information about side effects, while $45 \%$ get information about drug interactions. Those figures are consistent across all insurance types and regions, with Medicaid patients receiving slightly more information concerning side effects and drug interactions than other consumers. Remember-for this group-the pharmacist is most often the first line of information.

\section{PRESCRIBER COMMUNICATIONS ABOUT PRICE, QUALITY OF LIFE}

Despite the emphasis on the cost of health care in the media and among insurers and providers, survey data show that only slightly more than one half of patients report having discussions with their physicians about both quality of life and cost considerations when a course of treatment is chosen. In this respect, those covered by managed care plans are no different from indemnity patients. Medicare patients have somewhat more consultations about quality of life considerations, and Medicaid patients have slightly more discussions that include only cost considerations. Across all groups, 30\% say they discuss only quality of life issues with their physicians. Unfortunately, this survey did not explore where patients go for information about costs or whether they perceive cost as an influence on treatment decisions.

Other data from the survey suggest that most consumers are simply unaware that their physicians may be subject to prescription controls (60\% say there are no controls; $25 \%$ do not know whether such controls exist). By implication, they may not be aware of other ways in which cost management affects treatment.

Managed care consumers have a higher level of awareness about such restrictions than indemnity patients, but not high enough to reflect the actual disparity in the level of restriction between the two types of coverage. Of managed care consumers, 18\% know their physicians are subject to prescribing restrictions; $54 \%$ say there are no restrictions, and $27 \%$ are not sure. Just below $10 \%$ of indemnity patients know their physicians follow prescribing guidelines, $75 \%$ say there are no restrictions, and $16 \%$ are unsure whether their plan imposes restrictions.

\section{MEDICATION PRICES: LOOKING FOR FAIRNESS}

Consumers' perception of pharmaceutical price fairness - they believe that drug prices are too high-is at odds with the way they see their own experience. Across all regions and insurer types, $60-70 \%$ of survey respondents who have insurance believe the cost of prescription drugs is unfair, but $62 \%$ of managed care consumers and $57 \%$ of indemnity consumers feel they

Continued on page 498 


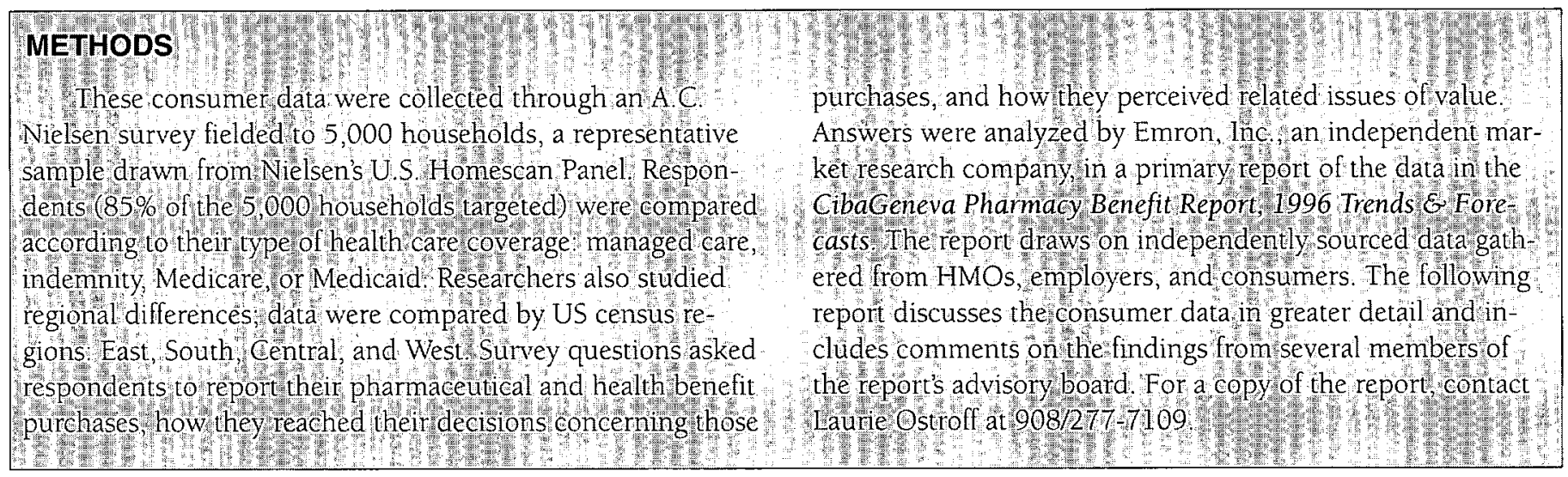

pay "just the right amount" for medication as a proportion of their overall health care expenditures.

Pat Wilson, president of Associates $\&$ Wilson, a consultant to pharmacy benefit management companies and self-insured employers, says she is more surprised by the $11.6 \%$ of respondents who say they believe they should not have to pay anything. "So many people still feel health care should be totally provided by their employers-but employers have been burned by overutilization. Nothing educates consumers more than sharing the cost of the services they need, even in the form of a low copayment."

When reporting actual personal expenditures rather than opinions, about $45 \%$, across all regions and insurance types, told the surveyors they spend less than $\$ 10$ per month on prescription medications; $38 \%$ spend between $\$ 11$ and $\$ 50$ per month (Table 3). More than $80 \%$ of both managed care and indemnity consumers report spending less than $\$ 50$ a month, and, despite the lower copayments associated with managed care coverage, there is little difference between the two groups. The outof-pocket differences are less pronounced, even at higher monthly cost levels, between managed care and indemnity consumers than between Medicare and other insurance types (Table 4). Medicare patients are traditionally higher users of all medical ser- vices, including pharmaceuticals. As expected, Medicare patients are less satisfied than other groups with the amount they spend. Yet, $40 \%$ feel they pay just the right amount; $30 \%$ feel they pay too much; while $28 \%$ are undecided.

Michael Dillon, who was also surprised by the number of consumers who consider drug prices to be unfair, commented that the pharmaceutical companies and employers who share the cost of the drug benefit with consumers "haven't done a very good job of demonstrating the value of drug therapies."

\section{WHAT CONSUMERS FIND IMPORTANT IN A BENEFIT PLAN}

A clear majority (more than $70 \%$ ) of all consumers consider the inclusion of a pharmacy benefit to be a "very important" criterion in their decision to purchase a health plan. Employers are well aware of this. But as Dillon points out, even though the drug benefit is considered important, when consumers are asked to rank a number of purchasing criteria (this survey did not), the price and choice of physician are usually ranked ahead of inclusion of a drug benefit.

Dillon's point that employers and insurers have not done enough to demonstrate the value of the benefit seems bome out by questions about the extent to which consumers are using it. For example, even though employers and insurers are sold on the concept of managing health through wellness programs and disease management, consumers have not attached much importance to those aspects of their health benefit. Of HMOs, $65 \%$ offer workplace wellness programs; almost $70 \%$ have some kind of disease management program in place. ${ }^{1}$ Yet, half of managed care consumers surveyed did not know whether they have access to diseasemanagement programs, and fewer than $4 \%$ report having used them. More take advantage of wellness programs$29 \%$-but only $50 \%$ are aware they have access to these programs and 25\% are unsure whether they have access (Table 4).

Pat Wilson expressed a different perspective on those figures. "When a disease-management program is done well, it begins by identifying exactly those covered members who fit the profile of being at risk for the targeted disease. Then the plan reaches out to specific patients. Other members in the plan do not necessarily know about the program-they have no need for it."

\section{NONPRESCRIPTION MEDICATION PURCHASES: PROFESSIONAL ADVICE LACKING}

In contrast to the many sources of information consumers consult about prescription medication, $45 \%$ do not 
seek any professional advice about nonprescription medication purchases (Table 1). Those who do ask pharmacists more often $(75 \%)$ than physicians $(60 \%)$. This behavior is consistent across managed care and indemnity consumers. Again, an even higher percentage of Medicare and Medicaid consumers report they would speak to the pharmacist before purchasing a nonprescription product.

All consumers report that they consult advertising for both nonprescription and prescription products, and they highly value the information they get from these ads. Fully one half reported that they consider pharmaceutical advertisements as educational, helping them become "more informed consumers." It is not surprising that $42 \%$ say they will base their next purchase decision on such advertising.

Dillon commented that such advertising poses difficult issues for physicians and pharmacists trying to follow formulary guidelines in managing treatment and costs. Such ads, by regulation, must include full therapeutic information (e.g., dosing, side effects, course of treatment, and outcomes). "Patients are now proposing their own regimens," he said. "Physicians and pharmacists are doing their best to determine why the patient is or is not responding to the originally prescribed medication, and they are also explaining their choices as well as they can. Of course, these considerations also give providers a chance to take another look at the treatment and formulary guidelines as they affect a particular patient, to see whether there's been a flaw in the decision-making cascade." The data re- inforce Dillon's point: just below 20\% say they ask their physician about advertised products; just above $20 \%$ say they ask their pharmacist.

Direct-to-consumer advertising is particularly heavy when manufacturers promote highly successful prescription products as their patent protection expires and/or as drugs become available as nonprescription (Rx-to-OTC switch) products. Consumers clearly respond. Roughly $75 \%$ say they are likely to extremely likely to purchase switch products. Given this response, direct-to-consumer advertising will probably increase, rather than decrease as benefit managers would prefer.

\section{IMPLICATIONS FOR PHARMACISTS IN MANAGED CARE}

This consumer survey focused narrowly on behavior and perceptions concerning the cost and value of the pharmacy benefit. The resulting data provide unexpected insights into consumer attitudes about pharmacists as well. Consumers have mixed feelings about the value of prescription medications, a superficial understanding of what their benefit plan offers, but a consistently high level of trust in the pharmacist, whom they regard as a dependable source of medical information.

Health plans empowering pharmacists to offer cognitive services at the point of purchase are likely to increase customer satisfaction and member retention. Plans hoping to realize big savings from mail-service pharmacies should also determine ways through which to maintain patient contact with a pharmacist if they expect patients to adopt long distance dispensing compliantly. Plans in which pharmacists develop guidelines for health and diseasemanagement programs-and in which the dispensing pharmacist aids in the program implementation-are tapping a vital resource. These professionals can apply their drug knowledge to inform patients and encourage compliance.

As more consumers receive benefits through managed care plans, the U.S. patient base is entering "an organized system of health care delivery rather than merely accessing a payment system," as Chernov draws the distinction. Such systems depend on knowledgeable patient handling at every point of contact. This survey indicates that consumers value the pharmacist as exactly that kind of provider. The pharmacist and plan now have to determine whether that trust is justified by the level of patient counseling pharmacists actually provide. Do they probe, discover patient problems with prescribed treatments, and identify complications and side effects? Do they have the ability to access relevant data and implement quality practice guidelines at the point of dispensing? Moving beyond compliance monitoring, will pharmacist interaction with the patient have a positive effect on the overall quality of the treatment regimen? Hopefully, the near future will hold answers.

\section{Reference}

1. CibaGeneva Pharmacy Benefit Report, 1996 Trends \& Forecasts. Figures drawn from an independent survey designed by Emron, Inc., Warren, NJ, 1996 